\title{
ESTUDO DA EVASÃO UNIVERSITÁRIA EM CONTEXTOS EMERGENTES: DESAFIOS À PERMANÊNCIA ESTUDANTIL
}

\author{
Thiago Ingrassia Pereira ${ }^{1}$ \\ https://orcid.org/0000-0002-5558-7836 \\ Kelly Cristina dos Reis ${ }^{2}$ \\ https://orcid.org/0000-0002-8297-7864
}

RESUMO: A expansão do acesso à educação superior no Brasil verificada a partir de políticas públicas federais permitiu a entrada de segmentos sociais historicamente afastados da universidade. Ao completar uma década, é possível observar as potencialidades e limites do REUNI, avançando a análise das questões relativas ao acesso para os dilemas da permanência estudantil. Nesse sentido, este trabalho investiga a evasão de alunos(as) em um Campus de uma universidade federal originada nesta política pública do sul do Brasil. Por meio de dados do sistema acadêmico da Instituição e considerando pesquisas e debates já realizados, objetiva-se compreender os desafios postos à permanência dos(as) estudantes neste contexto emergente. Examina-se este cenário a partir de referenciais teórico do campo da Sociologia da Educação. Dessa forma, resultados parciais da investigação apontam para um cenário de democratização inconclusa da universidade brasileira, no qual a evasão é multicausal e reflete os dilemas da permanência estudantil.

PALAVRAS-CHAVE: universidade, evasão, permanência estudantil.

\section{STUDY OF UNIVERSITY EVASION IN EMERGING CONTEXTS: CHALLENGES TO STUDENT CONTINUITY}

ABSTRACT: The expansion of access to higher education, verified through federal public policies, allowed the entry of social segments historically away from the university. Upon completing a decade, it is possible to observe the potential and limits of REUNI,

\footnotetext{
${ }^{1}$ Doutor e Pós-Doutor em Educação.Professor da Universidade Federal da Fronteira Sul (UFFS) Campus Erechim.Programa de Pós-Graduação Profissional em Educação (PPGPE).Programa de Pós-Graduação Interdisciplinar em Ciências Humanas (PPGICH).Erechim, Rio Grande do Sul, Brasil.thiago.ingrassia@uffs.edu.br ${ }^{2}$ Mestra pelo Programa de Pós-Graduação Profissional em Educação (PPGPE) e Servidora Técnico-Administrativa em Educação.Universidade Federal da Fronteira Sul (UFFS) Campus Erechim.Erechim, Rio Grande do Sul, Brasil.kellycristinareis08@gmail.com
} 
moving forward the analysis of issues related to access towards the dilemmas of the student's permanence. In this sense, this work investigates the evasion of students on a Campus of a federal university in southern Brazil. Using data from the Institution's academic system and considering research and debates already carried out, the objective is to understand the challenges posed to the permanence of students in this emerging context. This scenario is examined based on theoretical references in the field of Sociology of Education. Thus, partial results of the investigation point to a scenario of unfinished democratization of the Brazilian university, in which dropout is multi-causal and reflects the dilemmas of student permanence.

KEYWORDS: university, evasion, student permanence.

\section{ESTUDIO DE EVASIÓN UNIVERSITARIA EN CONTEXTOS EMERGENTES: DESAFÍOS PARA LA PERMANENCIA DEL ESTUDIANTE}

RESUMEN: La expansión del acceso a la educación superior en Brasil verificada a partir de políticas públicas federales permitió la entrada de segmentos sociales históricamente retirados de la universidad. Al final de una década, es posible observar las potencialidades y los límites de REUNI, avanzando el análisis de los problemas de acceso a los dilemas de la permanencia de los estudiantes. En este sentido, este trabajo investiga la deserción de estudiantes en un campus de una universidad federal originada en esta política pública del sur de Brasil. A través de los datos del sistema académico de la institución y considerando las investigaciones y debates ya realizados, el objetivo es comprender los desafíos que plantea la permanencia de los estudiantes en este contexto emergente. Este escenario se examina desde el marco teórico del campo de la sociología de la educación. Así, los resultados parciales de la investigación apuntan a un escenario de democratización inacabada de la universidad brasileña, en la que la deserción es multicausal y refleja los dilemas de la permanencia de los estudiantes.

PALABRAS CLAVE: universidad, evasión, permanencia estudiantil.

\section{Primeiras palavras}

Refletir sobre os processos excludentes de acesso e permanência na universidade pública brasileira é uma tarefa que envolve um conjunto de pesquisas nos campos das ciências sociais e educação nas últimas décadas. 
Encontramos críticas ao elitismo da universidade nos trabalhos de Florestan Fernandes $(2004 ; 1975)$, assim como a análise do papel social da universidade em sua relação com processos mais amplos de transformação social na obra de Paulo Freire (1994).

O que esses autores têm sugerido é que a universidade possa estar mais próxima das questões sociais e que, na medida do possível, contribua para a superação dos problemas que assolam nosso povo. Certamente, a universidade não é uma instituição capaz, por si só, de promover profundas alterações no cenário político e cultural, mas é um dos canais, por excelência da crítica, que promove a denúncia e a construção de um novo projeto societário que anuncia uma sociedade mais inclusiva e justa.

Nesse sentido, refletir sobre a universidade na América Latina sugere sua compreensão como instituição social (CHAUÍ, 2001) em relação contraditória com o quadro de aguda desigualdade social. A discussão sobre mecanismos de acesso e permanência de estudantes das camadas populares é um tema da agenda, assim como a construção de um novo e sofisticado entendimento acerca da evasão universitária, principalmente em contexto emergente de novos arranjos universitários como os que vislumbramos no Brasil na última década.

Verifica-se o aumento do quantitativo de estudantes universitários no Brasil nos últimos quinze anos, dando sequência ao cenário de expansão observado nos anos 1990. Contudo, se naquela ocasião a expansão ocorreu via a diversificação das instituições superiores e pela oferta privada, atualmente um conjunto de políticas públicas capitaneadas pelo governo federal é responsável pelos indicadores positivos de acesso à educação superior.

Em cenário de instabilidade política, o atual contexto mostra-se desafiador no que tange à consolidação das novas instituições públicas criadas recentemente, assim como à continuidade do processo de expansão de matrículas, considerando as demais políticas de compra de vagas públicas em instituições privadas e o financiamento estudantil.

Dessa forma, este trabalho investiga a evasão de alunos(as) em um Campus de uma universidade federal construída a partir de política pública (REUNI) e da mobilização social no sul do Brasil. Considerando o histórico da nova instituição e dados de seu sistema acadêmico, além de pesquisas já realizadas e discussões atuais no âmbito desta comunidade universitária, objetiva-se compreender os desafios postos à permanência dos(as) estudantes neste contexto emergente.

Considerando os debates atuais sobre o conceito de evasão na educação superior, o artigo retoma brevemente o contexto da expansão de matrículas 
universitárias verificado no início desse século, situando a instituição que será examinada como parte de uma estratégia de interiorização da universidade pública. Além disso, a experiência analisada permite reconhecermos os limites e as possibilidades de uma universidade construída na fronteira entre a pressão social e a intencionalidade política do governo. São esses atores que irão caracterizar a nova universidade que nasce em meio aos antigos desafios verificados no prolongamento escolar das classes populares.

\section{Contextualizando a expansão universitária nos anos 2000}

A universidade brasileira é uma instituição recente se comparada ao observado no cenário internacional. Inaugurada no contexto dos anos 1920, é resultado do processo de aglutinação de faculdades e institutos isolados que surgiram durante o século XIX. É uma instituição que se aproxima de uma história milenar no contexto ocidental, mas que no Brasil ainda não tem um século de existência (ROSSATO, 2005).

Acompanhando os vários momentos que a sociedade brasileira viveu durante o século $\mathrm{XX}$, a universidade foi se constituindo por meio de traços elitistas, produzidos pela estrutural desigualdade social do Brasil. Passando por várias reformas, a instituição convive com forte influência estadunidense no período pós-Golpe Militar de 1964.

O cenário de abertura democrática nos anos 1980 renova o debate sobre a universidade e o seu papel formativo inserida em um projeto democrático de país. As sucessivas crises econômicas e a manutenção de quadros agudos de concentração de renda e poder político, oriundos de uma transição democrática negociada intraelites, constrangem a relação da universidade com a sociedade, gerando um afastamento da instituição de demandas populares.

O sistema de educação superior brasileiro se expandiu de forma concentrada e privada a partir da década de 1990 (NEVES; RAIZER; FACHINETTO, 2007), apostando em novos modelos operacionais, como a educação a distância (EAD) e em modelos organizacionais, como centros universitários, faculdades e instituições comunitárias (complexificação do sistema).

Aprofunda-se a privatização da universidade no Brasil e fomenta-se um quadro de mercadorização da educação e, em especial, do nível superior, momento em que ações de instituições educacionais são negociadas com forte valorização na bolsa de valores (OLIVEIRA, 2009). Dessa forma, o histórico excedente que se origina pela pressão pelo aumento da escolarização no contexto de reforma produtiva do capitalismo é encaminhado pela via do mercado 
nos anos 1990, destituindo o acesso aos níveis mais altos de escolarização da condição de direito social.

Esse quadro começa a mudar, pelo menos com o retorno do Estado como agente de fomento, a partir do início do Governo Lula, em 2003, quando o Estado brasileiro passa a assumir a implementação de políticas de expansão. O diagnóstico que gerou um ciclo virtuoso de políticas públicas de expansão do acesso à educação superior sinalizava para uma instituição elitista, privada, concentrada nas capitais e áreas metropolitanas, e com um passivo enorme da presença de segmentos sociais não brancos e de pobres.

Por meio da ação estatal, foram tomadas medidas que resultaram na ampliação de vagas públicas em instituições superiores de ensino. As principais políticas construídas a partir de 2003 foram: (a) Programa Universidade para Todos (ProUni); (b) Universidade Aberta do Brasil (UAB); (c) Programa de Apoio a Planos de Reestruturação e Expansão das Universidades Federais (REUNI); (d) reorganização do Fundo de Financiamento ao Estudante do Ensino Superior (FIES).

Ao direcionar essas políticas públicas tanto em direção à esfera pública quanto à privada, o Governo Lula gerou um cenário complexo e contraditório, no qual a expansão verificada abriu um novo debate sobre sua efetividade na construção de um novo arranjo universitário no país. De qualquer forma, é inegável a expansão quantitativa das matrículas, pois, segundo dados do Censo da Educação Superior 2016, na última década passamos de 4.944.877 (2006) para 8.055.254 (2016) matrículas, representando 62,8\% de crescimento, com uma média de crescimento anual de $5 \%$ (BRASIL, 2017).

Diante desse cenário, cabem duas constatações: (1) o crescimento do número de matrículas na educação superior é resultado do conjunto de políticas públicas do Governo Lula, tanto as referidas anteriormente, como as Ações Afirmativas (Cotas), o Exame Nacional do Ensino Médio (ENEM) e o Sistema de Seleção Unificado (SiSU); (2) o aumento de pessoas que chegaram à educação superior passa a demandar políticas de permanência e o enfrentamento da evasão universitária. Por isso, torna-se relevante examinar o fenômeno da evasão em uma nova universidade pública federal construída a partir da política do REUNI.

\section{A UFFS como universidade emergente}

Instituída pela Lei no 12.029, de 15 de setembro de 2009, a Universidade Federal da Fronteira Sul (UFFS) é a décima primeira de quatorze uni- 
versidades federais criadas durante o Governo Lula (2003-2010). Sua criação teve origem na mobilização de segmentos sociais dos três estados do Sul do Brasil organizados no chamado "Movimento Pró-Universidade", que buscavam a materialização das políticas públicas, promovidas pelo Governo Federal, voltadas à expansão e interiorização da educação superior pública, como o REUNI.

Seus seis campi ${ }^{3}$ estão instalados na chamada Mesorregião Grande Fronteira do Mercosul, região historicamente carente de oferta de educação superior gratuita, e que abrange cerca de 400 municípios do Noroeste do Rio Grande do Sul, Oeste de Santa Catarina e Sudoeste do Paraná. São ofertadas, anualmente, mais de duas mil vagas em mais de 40 cursos de graduação e 15 Programas de Pós-Graduação.

Como desdobramento do seu processo de concepção, a UFFS adotou como um de seus princípios ser "popular". Essa marca institucional, embora cercada de tensão e contradições (DAMBROS, 2015; PEREIRA, 2015), se materializa de forma mais efetiva na sua política de acesso, ao criar condições para que cerca de $90 \%$ do seu corpo discente seja oriundo da rede pública de ensino, o que faz da UFFS a instituição federal de educação superior (IFES) que mais integra estudantes de escola pública (RISTOFF, 2016).

Desde seu primeiro processo seletivo, realizado em 2010, a Instituição optou por não usar a forma tradicional de ingresso de estudantes, por meio de vestibular, preferindo utilizar a nota do ENEM como referencial, mais a política afirmativa denominada "fator escola pública", aplicando à nota do ENEM o índice de $10 \%$ para cada ano do ensino médio cursado pelo(a) candidato(a) na rede pública. Essa diretriz institucional provocou um quadro inédito nas IFES brasileiras, conforme indicam dados de seu primeiro grupo de ingressantes:

[...] 93,68\% dos estudantes da UFFS são oriundos da escola pública; $79 \%$ não cursaram pré-vestibular; $87 \%$ são oriundos de famílias com renda de até cinco salários mínimos; em sua maioria são trabalhadores assalariados e $87 \%$ representam a primeira geração da família a chegar a um curso universitário. (ROTTA; VITCEL; ANDRIOLI, 2012, p. 61).

A partir de 2013, a UFFS passou a adotar o que prevê a legislação nacional de reserva de vagas nas IFES, considerando, assim, além da trajetória escolar dos(as) candidatos(as) (critério bastante valorizado nos três primeiros processos seletivos da Instituição), o perfil econômico das famílias e a carac-

\footnotetext{
${ }^{3}$ Erechim, Cerro Largo e Passo Fundo no Rio Grande do Sul, Chapecó em Santa Catarina (onde também está instalada a Reitoria) e Laranjeiras do Sul e Realeza no Paraná.
} 
terização étnico-racial da população ${ }^{4}$. No âmbito de sua autonomia, a UFFS optou por reservar vagas a candidatos(as) que tivessem cursado integralmente o ensino médio em escola pública na porcentagem equivalente ao de estudantes matriculados(as) no ensino médio da rede pública de cada estado em que a Instituição está instalada. Dessa forma, foi possível manter a média de $90 \%$ de universitários(as) oriundos(as) de escola pública.

Ainda em 2013, a UFFS instituiu outras duas políticas de acesso: o Programa de Acesso e Permanência dos Povos Indígenas (PIN), que reserva duas vagas suplementares por curso de graduação a estudantes indígenas e 0 Programa de Acesso à Educação Superior da UFFS para Estudantes Haitianos (PROHAITI), que oferta vagas suplementares nos cursos de graduação a imigrantes haitianos(as) por meio de processo seletivo especial. No processo de seleção para ingresso em 2018, a Instituição passou, ainda, a reservar vagas para pessoas com deficiência, atendendo legislação em vigor.

Destaca-se que, em 2014, a UFFS a deriu ao Sistema de Seleção Unificada (SiSU) do Ministério da Educação (MEC). A adesão não afetou a política de reserva de vagas da Instituição. Assim, a política de acesso da UFFS apresenta significativos avanços em relação às arbitrárias desigualdades que ocorrem no âmbito da educação superior, uma vez que cria condições para entrada de segmentos sociais historicamente afastados dos espaços universitários.

Nesse sentido, este breve histórico indica que a construção de uma universidade como a UFFS é parte de um contexto em que a política pública encontra uma demanda social expressiva. Contudo, exatamente por sua condição histórica, a nova universidade não se pretende apenas mais uma universidade em moldes tradicionais, mas uma instituição inovadora que alie a excelência acadêmica com o compromisso social.

De certa forma, a intenção institucional de ser uma universidade "pública e popular" representa esse novo projeto, ousado e historicamente necessário. A UFFS surge num momento de debates sobre a chamada "crise da universidade". Com o objetivo de passar "da ideia de universidade à universidade de ideias", Boaventura de Sousa Santos (2005) examina a "crise" da universidade tradicional por meio de três variantes: a) crise de hegemonia, b)

\footnotetext{
${ }^{4}$ A Lei no 12.711, sancionada em 29 de agosto de 2012, garante a reserva de $50 \%$ das vagas ofertadas por universidades, institutos e centros federais, em cada processo seletivo, curso e turno, a estudantes que cursaram o ensino médio integralmente na rede pública. Metade das vagas ofertadas dentro dessa porcentagem deve ser destinada a estudantes de famílias com renda mensal per capita igual ou inferior a 1,5 salário mínimo. E, em cada faixa de renda, devem ser reservadas vagas a estudantes autodeclarados(as) pretos(as), pardos(as), indígenas e pessoas com deficiência de forma proporcional ao censo realizado pelo Instituto Brasileiro de Geografia e Estatística (IBGE) no estado no qual a instituição está instalada.
} 
crise de legitimidade e c) crise institucional.

A crise de hegemonia estaria ligada à compreensão de que a universidade não é a única nem a mais importante instituição produtora do conhecimento. Sobre a legitimidade, é apontado o distanciamento da instituição diante dos problemas concretos das pessoas e, por fim, a crise institucional estaria relacionada às outras duas e encontraria sua razão no debate do (novo) modelo universitário a ser criado.

Para Santos (2005), o contexto social condiciona as mudanças da universidade. Entre 1995 e 2005, a crise institucional se consolidou por meio da tensão entre a autonomia da instituição e os grupos sociais de pressões, notadamente em duas direções: os hiperprivatistas, voltados ao mercado, e os hiperpublicistas, problematizando as funções sociais da universidade. Assim, teríamos dois desafios: 1) expansão e transnacionalização do mercado de serviços universitários e 2) pressões advindas da crítica social (perda da hegemonia) na produção do conhecimento (desdobra-se na discussão epistemológica).

No caso do contexto latino-americano, temos algumas "encruzilhadas" da universidade em sua relação com a sociedade e o Estado. No presente, a demanda por formação é tanto uma exigência do contexto econômico como do político, tendo em vista os projetos de mobilidade social e do próprio tensionamento do capitalismo hegemônico. Tendo em vista esse cenário,

[...] no horizonte das alternativas de um projeto social emancipatório, liderado pelas classes populares e demais forças políticas progressistas na América Latina, encontra-se, também, a utopia de uma universidade que priorize a formação dos setores populares, e fomente novos processos na produção e socialização do conhecimento necessário à emancipação social, que é tão fortemente acalentada como um projeto de futuro mais humanizado para todos. Nessa perspectiva, despontam nas últimas décadas, diferentes projetos alternativos de universidade, concebidos desde o horizonte político das classes populares, dentre os quais destacamos: Universidade do Trabalhador; Universidade Solidária da Organização Popular; Universidade da Integração na América Latina (UNILA); Universidade da Fronteira Sul (UFFS); Universidade Popular dos Movimentos Sociais (UPMS) (ZITKOSKI, 2013, p. 18-19).

Assim, os novos modelos de universidade que emergem no Brasil precisam de monitoramento, análise e reflexão permanente. $O$ desafio reside em atuar localmente, valorizando práticas e saberes da comunidade regional, tendo em vista as questões que acontecem no mundo contemporâneo (CER- 
DEIRA, 2016). A UFFS é uma experiência relevante para o exame dos limites e das possibilidades da educação superior na promoção de um projeto societário inclusivo na América Latina. Assim, examinar a evasão apresenta um grande potencial explicativo aos desafios postos à universidade no atual contexto emergente de novos sujeitos e currículos.

\section{Evasão na UFFS: dados para o debate}

A evasão discente na educação superior é um problema que atinge todos os tipos de instituição, independente da sua categoria administrativa e da sua forma de organização acadêmica, promovendo, na perspectiva de Fialho (2014), prejuízos de ordem econômica, social e cultural tanto para as instituições e a sociedade como para os próprios indivíduos. Estudo realizado por Silva Filho et al (2007) mostra que, entre os anos 2000 e 2005, a evasão anual média nas instituições de educação superior públicas foi de $12 \%$ enquanto nas privadas o índice chegou a $26 \%$. Segundo informação disponibilizada no portal do $\mathrm{MEC}^{5}$, no ano de 2010, 11,4\% dos(as) estudantes abandonaram os cursos de graduação para os quais foram admitidos(as). No ano de 2014, esse número saltou para $49 \%$.

Definir o conceito de evasão é uma preocupação justificada uma vez que os critérios de conceituação utilizados pela pesquisa refletem na maior confiabilidade dos seus resultados. Segundo Schmitt (2014), embora não haja, no Brasil, uma convenção acerca do termo, ele historicamente está ligado às perdas estudantis. Para o MEC, evasão "é a saída definitiva do aluno de seu curso de origem, sem concluí-lo ou a diferença entre ingressantes e concluintes, após uma geração completa" (BRASIL/MEC, 1997, p.19).

Fritsch $(2015$, p.2) caracteriza a evasão como "um processo de exclusão determinado por fatores e variáveis internas e externas às instituições de ensino". Para Bueno (1993, apud MEC, 1997) a evasão difere-se da exclusão. Enquanto na evasão a responsabilidade recai sobre o(a) estudante, que opta por desligar-se por vontade própria, na exclusão há uma admissão de responsabilidade da instituição e de tudo que a cerca. Ristoff (1999) faz uma distinção entre evasão e mobilidade, em que a primeira corresponde ao abandono dos estudos e a segunda está ligada ao fenômeno de migração do(a) estudante para outro curso da mesma instituição ou de outra.

${ }^{5}$ Disponível em: http://portal.mec.gov.br/ultimas-noticias/212-educacao-superior-1690610854/40111-altos-indices-de-evasao-na-graduacao-revelam-fragilidade-do-ensino-medio-avalia-ministro. Acesso em: 25 out. 2017. 
O MEC, reconhecendo as limitações do seu conceito de evasão, classificou o fenômeno nas seguintes modalidades:

1) evasão de curso: quando o estudante desliga-se do curso superior em situações diversas tais como: abandono (deixa de matricular-se), desistência (oficial), transferência ou reopção (mudança de curso), exclusão por norma institucional; 2) evasão da instituição: quando o estudante desliga-se da instituição na qual está matriculado; 3) evasão do sistema: quanto o estudante abandona de forma definitiva ou temporária o ensino superior (BRASIL, 1997, p.20).

Diante dessas definições, percebe-se a complexidade do fenômeno em pauta. Encontramos em Paulo Freire a ideia de que a evasão escolar seria, sobretudo, definida em termos da exclusão ("expulsão") dos(as) estudantes. Para Freire (2005), a instituição escolar apresenta-se refratária aos anseios e necessidades do corpo discente, principalmente dos(as) estudantes provenientes das classes populares. A partir de sua experiência na gestão da Secretaria Municipal da Educação de São Paulo, o autor reflete acerca do processo de abandono escolar e seus desdobramentos em termos políticos, econômicos e culturais.

Dessa forma, a evasão seria, para além de um problema quantitativo e econômico, uma questão social que demandaria uma postura política em seu enfrentamento. Portanto, a leitura freireana sinaliza à relação intrínseca entre a desigualdade social e a desigualdade escolar, sendo a evasão uma expulsão em cenário de concentração de riquezas e fragilidade do tecido social.

Com base nessas perspectivas, centramos a análise nos processos de ociosidade de vagas nas IFES. Entendemos que existe um campo ainda pouco explorado, relacionado à evasão nas universidades federais implantadas nos últimos 15 anos. Cardoso e Ludovico (2017), ao analisarem o Banco de Teses do Instituto Brasileiro de Informação em Ciência e Tecnologia (IBICT), no período de publicação de 2011 a 2016, identificaram 27 (vinte e sete) teses e dissertações sobre o tema evasão na educação superior. Dessas, apenas três pesquisaram o fenômeno em universidades criadas recentemente e apenas uma estudou a evasão em uma universidade inteiramente nova ${ }^{6}$.

A existência dessa lacuna é que nos motiva a estudar o problema da evasão em uma dessas novas instituições. Na UFFS encontra-se uma instituição que se vê envolta em uma série de contradições e dilemas acerca do acesso e

${ }^{6}$ Das 14 universidades criadas entre 2003 e 2010, cinco são inteiramente novas (UFFS, UNILA, UNILAB, UNIPAMPA e UFABC), e nove são originárias de outras universidades federais ou escolas técnicas. 
da permanência de seu corpo discente.

Diante disso, um estudo realizado pelo Grupo de Pesquisa em Educação Popular na Universidade (GRUPEPU/CNPq), com base em dados disponibilizados pela Pró-Reitoria de Graduação da UFFS, apresentou dados quantitativos sobre as taxas de ocupação e evasão na Instituição nos seus primeiros anos de atividade. $O$ Grupo pesquisou as taxas de evasão por curso e para isso estabeleceu a comparação entre o número de estudantes que ingressaram na Universidade e o número de estudantes com matrícula ativa ${ }^{7}$.

No âmbito do Campus Erechim, foco desse artigo, a pesquisa mostrou que, no período de 2010 a 2013, a evasão foi de $42 \%$ nos oito cursos de graduação ofertados na época ${ }^{8}$, sendo que as taxas médias foram maiores nos cursos de licenciatura (52\%) em comparação aos cursos de bacharelado (28\%). O auge do processo de evasão ocorreu em 2011 quando 52\% do total de ingressantes nos cursos ofertados evadiram. Naquele ano, as Licenciaturas em Ciências Sociais e Filosofia tiveram as maiores taxas de evasão, chegando a $75 \%$ e $76 \%$, respectivamente.

Os cursos que tiveram maior média de evasão no período pesquisado também foram as Licenciaturas em Filosofia (66\%) e Ciências Sociais (58\%). O Bacharelado em Arquitetura e Urbanismo teve a menor taxa média de evasão no período (22\%). Em 2013, o curso registrou o menor índice de evasão dentre todas as graduações do Campus, chegando a $12 \%$.

Com base no cruzamento de dados disponibilizados pela Pró-Reitoria de Graduação da UFFS, e utilizando os mesmos parâmetros usados pelo GRUPEPU, foi possível verificar que nos anos de 2014 e 2015 os números permaneceram elevados. A média de evasão no período foi de $26 \%$ nos cursos de bacharelado e $53 \%$ nos cursos de licenciatura, não apresentando diferença significativa em relação aos índices apontados pelo GRUPEPU.

O curso Interdisciplinar em Educação do Campo: Ciências da Natureza, ofertado a partir de 2013, teve taxa de evasão similar às demais licenciaturas. Entre 2013 e 2015, verificou-se uma média de evasão de 47\% nesse curso. Se tomarmos como base o período de 2010 a 2015 e os oito cursos ofertados pelo Campus desde o primeiro processo seletivo, verificaremos que cerca de $40 \%$ de seus estudantes abandonaram os cursos nos quais ingressaram antes de concluí-los.

\footnotetext{
${ }^{7}$ As matrículas trancadas são consideradas ativas uma vez que o estudante mantém o vínculo com a Instituição e a vaga não pode ser disponibilizada para oferta em novos processos seletivos.

${ }^{8}$ Bacharelados diurnos em Agronomia, Arquitetura e Urbanismo e Engenharia Ambiental. Licenciaturas noturnas em Pedagogia, Ciências Sociais, Filosofia, História e Geografia.
} 
Para Lobo (2012, p. 26), “medir a evasão não trata só de verificar um 'saldo em caixa', ou seja, quantos alunos entraram menos quando saíram, mas quem entrou e quem saiu e por quais razões". O levantamento de índices sobre evasão, seja em um curso, uma instituição, ou em todo o sistema, representa apenas o primeiro passo para o entendimento deste fenômeno tão complexo. A efetividade do combate deste problema depende da identificação, da análise e da compreensão de fatores ligados a três dimensões interdependentes: as idiossincrasias dos(as) estudantes, o contexto interno à instituição e o contexto externo à instituição.

Identificar esses fatores não é tarefa fácil. No estudo realizado por Zago, Paixão e Pereira (2016) com estudantes evadidos(as) de cursos ofertados na UFFS - Campus Erechim, constatou-se a dificuldade de obter esses dados. Os pesquisadores enviaram questionário eletrônico para 204 estudantes desistentes ${ }^{9}$ no período de 2010 a 2014 e receberam retorno de aproximadamente $10 \%$, o que ficou aquém do esperado. Mesmo assim, foi possível constatar naquele contexto processos significativos de evasão por mobilidade.

Essa experiência mostra o quão importante é verificar os fatores que influenciam na evasão enquanto o(a) estudante ainda mantém vínculo com a Instituição. Criar espaços institucionais para ouvir o corpo discente é uma decisão que pode ser altamente significativa em termos de produção de subsídios analíticos à compreensão dos dilemas da permanência estudantil. Nesse sentido, em Reunião Aberta promovida no Campus Erechim, em agosto de 2017, pelo Grupo de Trabalho (GT) Acesso, Permanência, Moradia Estudantil, Retenção e Evasão da II Conferência de Ensino, Pesquisa e Extensão da UFFS, ouviu-se segmentos estudantis.

Dentre as causas apontadas pelos(as) estudantes participantes dessa reunião, se destacam as de ordem econômica, que estão vinculadas ao alto custo de vida na cidade de Erechim, incompatível com os auxílios socioeconômicos ${ }^{10}$ ofertados pela Instituição, à falta de moradia estudantil e à baixa oferta de bolsas de ensino, iniciação científica, extensão, cultura e monitoria. Vale destacar que esses aspectos são presença constante em pesquisas sobre

\footnotetext{
${ }^{9}$ Conforme definições do Regulamento da Graduação da UFFS, estudante desistente é aquele que formaliza seu pedido de desistência por meio de requerimento específico e devidamente justificado.

${ }^{10} \mathrm{O}$ auxílio alimentação, que tem por objetivo auxiliar no custeio da alimentação de estudantes dos campi que possuam ou não restaurante universitário em funcionamento variou, no ano de 2017 , de $R \$ 40,00$ a R\$ 150,00, de acordo com o Índice de Vulnerabilidade Socioeconômica (IVS) do estudante selecionado. Já o auxílio transporte, que visa auxiliar no custeio do transporte público ou locado utilizado para deslocamento em função das atividades acadêmicas dos estudantes, variou de $\mathrm{R} \$ 30,00$ a $\mathrm{R} \$ 100,00$. O auxílio moradia, voltado ao custeio de locação de imóveis ou pensionato, variou de $R \$ 80,00$ a $R \$ 220,00$.
} 
a condição dos(as) estudantes universitários(as) no contexto internacional (CERDEIRA; CABRITO, 2014).

Também foram citadas como motivação para a evasão, as dificuldades de adaptação à dinâmica acadêmica e às exigências dos cursos e dos(as) professores(as) em função da deficiência da formação na educação básica. A localização geográfica do Campus, distante cerca de quinze quilômetros da cidade de Erechim, associada a uma logística deficitária de transporte coletivo, é outro ponto que, segundo os(as) estudantes, pesa na hora de decidir por abandonar o curso.

Chamaram a atenção os reiterados relatos de dificuldades de integração acadêmica e social. Os(as) discentes apontaram uma série de situações de preconceito, discriminação, e desrespeito vivenciada dentro da UFFS, mas principalmente junto à comunidade local, gerando dificuldades de criação de vínculos com a Instituição e com a própria cidade, e levando, em alguns casos, a quadros de depressão.

Ao analisarmos as causas mais frequentes de evasão apontadas por Lobo (2012), verificamos que muitas delas estiveram presentes nas falas dos(as) estudantes:

Inadaptação do ingressante ao estilo do Ensino Superior e falta de maturidade; formação básica deficiente; dificuldade financeira; irritação com a precariedade dos serviços oferecidos pela IES; decepção com a pouca motivação e atenção dos professores; dificuldades com transporte, alimentação e ambientação na IES; mudança de curso; e mudança de residência (LOBO, 2012, p.48).

Verifica-se que as motivações que levam à evasão são, de certa forma, homogêneas entre as instituições. No entanto, é imprescindível que cada instituição, e até mesmo cada campus, investigue e analise quais são as características intrínsecas ao seu âmbito de atuação para que seja possível evitar que perdas continuem acontecendo pelos mesmos motivos. O combate efetivo só é possível quando se entende claramente como a evasão se configura no espaço onde ela ocorre, considerando as suas idiossincrasias.

\section{Considerações finais}

O tema da evasão é uma preocupação dos gestores e militantes pela causa da educação superior pública no Brasil. As políticas públicas do Governo Lula influenciaram o incremento quantitativo de instituições e vagas públicas, 
constituindo quadro de expansão na última década. Contudo, essa dimensão do acesso necessita ser complementada com a dimensão da permanência dos(as) estudantes.

Nesse sentido, examinar o fenômeno da evasão é um tema relevante no contexto universitário nacional, em especial, nas novas instituições que configuram novas disposições institucionais. A ociosidade de vagas em instituições que representam a necessária expansão historicamente represada do sistema de educação superior brasileiro é um sintoma que merece atenção na atualidade.

A UFFS, como nova universidade criada a partir do REUNI e proveniente da mobilização social do sul do Brasil, pode sinalizar as circunstâncias que originam a expressiva "fuga" de estudantes, mesmo em uma instituição pública e gratuita. Compreendemos a evasão com um fenômeno multicausal, não podendo ser tratada de forma simplista a partir apenas de números. Dependendo do ponto de vista e considerando variáveis sociológicas, a evasão pode ser entendida como expulsão, principalmente dos segmentos populares.

Dessa forma, este trabalho, embasado em estudos empíricos e reflexões conceituais, sugere que a evasão origina-se tanto de dificuldades financeiras localizadas nos(as) estudantes do segmento popular (foco e com expressiva presença na UFFS) na manutenção de suas vidas, como em constrangimentos de adaptação às exigências universitárias.

É possível constatar que as desigualdades sociais impactam no percurso universitário. Por isso a expansão de vagas atende à demanda histórica, mas não é aspecto suficiente para produzir cenário de democratização da universidade. Observar-se, a partir do caso da UFFS campus Erechim, que a presença de segmentos sociais historicamente excluídos do acesso à universidade promove novos desafios relacionados à permanência e conclusão com sucesso de seu curso.

Novas pesquisas devem se debruçar sobre aspectos qualitativos que justificam a evasão, ainda mais em contextos emergentes de novas instituições que buscam aliar excelência acadêmica com compromisso social. Assim, torna-se relevante pensar sociologicamente a universidade em sua relação com o Estado e com a sociedade, situando o(a) estudante em seu meio.

\section{Referências}

BRASIL. Censo de Educação Superior 2016. Brasília: INEP, 2017. Disponível em: http://download.inep.gov.br/educacao_superior/censo_superior/do- 
cumentos/2016/notas_sobre_o_censo_da_educacao_superior_2016.pdf. Acesso em: 3 nov. 2017.

BRASIL. Ministério da Educação. Diplomação, retenção e evasão nos cursos de graduação em Instituições de Ensino Superior Públicas. Relatório da Comissão Especial de Estudos sobre Evasão nas Universidades Públicas Brasileiras, SESu/MEC-ANDIFES-ABRUEM. Brasília: MEC/SESu, 1997, 152p.

CARDOSO, D. F.; LUDOVICO, N. Estudo longitudinal sobre as pesquisas de evasão no Ensino Superior: Diretório IBICT. REFAS, São Paulo, v.3, n. 4, p. 1-18, jun. 2017.

CERDEIRA, M. L. M. Educação superior em contextos emergentes: a qualidade e a internacionalização. In: FRANCO, M. E. D. P.; ZITKOSKI, J. J.; FRANCO, S. R. K. (Org.). Educação superior e contextos emergentes. Porto Alegre: EDIPUCRS, 2016, p. 25-45.

CERDEIRA, M. L. M.; CABRITO, B. (Orgs). Custos dos estudantes do ensino superior português: para a compreensão da condição social e económica dos estudantes do ensino superior. Lisboa: EDUCA, 2014.

CHAUÍ, M. Escritos sobre universidade. São Paulo: Editora UNESP, 2001.

DAMBROS, M. Dilemas na constituição do sentido atribuído ao popular na Universidade Federal da Fronteira Sul. 2015. 109 f. Dissertação (Mestrado em Educação) - Universidade Federal da Fronteira Sul, Chapecó, 2015.

FERNANDES, F. Universidade e desenvolvimento. In: IANNI, O. (Org.). Florestan Fernandes: sociologia crítica e militante. São Paulo: Expressão Popular, 2004, p. 273-316.

FERNANDES, F. Universidade brasileira: reforma ou revolução? São Paulo: Alfa-Omega, 1975.

FIALHO, M. G. D. A evasão escolar e a gestão universitária: o caso da Universidade Federal da Paraíba. 2014. 106 f. Dissertação (Mestrado Profissional em Gestão em Organizações Aprendentes) - Universidade Federal da Paraíba, João Pessoa, 2014.

FREIRE, P. A educação na cidade. 6. ed. São Paulo: Cortez, 2005.

FREIRE, P. Cartas a Cristina. São Paulo: Paz e Terra, 1994.

FRITSCH, R. A problemática da evasão em cursos de graduação em uma universidade privada. In: Anais da 37ạ Reunião Nacional da ANPEd. Florianó- 
polis, out. 2015, 17f. Disponível em: http://37reuniao.anped.org.br/wp-content/uploads/2015/02/Trabalho-GT11-3986.pdf. Acesso em: 10 out. 2017.

LOBO, M. B. C. M. Panorama da evasão no ensino superior brasileiro: aspectos gerais das causas e soluções. ABMES Cadernos, Brasília, n. 25, p. 9-58, 2012.

NEVES, C. E. B; RAIZER, L.; FACHINETTO, R. F. Educação superior para todos? Acesso, expansão e equidade: novos desafios para a política educacional. Sociologias, Porto Alegre, v.9, n. 17, p. 124-157, jan./jun. 2007.

OLIVEIRA, R. P. de. A transformação da educação em mercadoria no Brasil. Educação \& Sociedade, Campinas, v. 30, n. 108, p. 739-760, out. 2009.

PEREIRA, T. I. Classes populares na universidade pública brasileira e suas contradições: a experiência do Alto Uruguai Gaúcho. Curitiba: CRV, 2015.

RISTOFF, D. Democratização do Campus: impacto dos programas de inclusão sobre o perfil da graduação. Cadernos do GEA, Rio de Janeiro, v.5, n.9, jan./ jun. 2016.

RISTOFF, D. Universidade em foco: reflexões sobre a educação superior. Florianópolis: Insular, 1999.

ROSSATO, R. Universidade: nove séculos de história. 2. ed. Passo Fundo: Ed. UPF, 2005.

ROTTA, E.; VITCEL, M. S.; ANDRIOLI, A. I. A Universidade Federal da Fronteira Sul e a sua experiência de inclusão por meio da instituição das cotas sociais. In: LUFT, H. M; FALKEMBACH, E.M.; CASAES, J. B. (Orgs.). Freire na agenda da educação: inclusão e emancipação - educação de jovens e adultos. Vol. 2. ljuí: Ed. Unijuí, 2012, p. 55-65.

SANTOS, B. de S. Pela mão de Alice: o social e o político na pós-modernidade. 10. ed. São Paulo: Cortez, 2005.

SCHMITT, R. E. A evasão na educação superior: uma compreensão ecológica do fenômeno como estratégia para a gestão da permanência estudantil. In: Anais do 10o Seminário de Pesquisa em Educação da Região Sul - Reunião Científica da ANPED. Florianópolis, out. 2014, 21f. Disponível em: http:// xanpedsul.faed.udesc.br/arq_pdf/690-0.pdf. Acesso em: 29 de out. 2017.

SILVA FILHO, R. L. L. et al. A evasão no Ensino Superior brasileiro. Cadernos de Pesquisa, São Paulo, v. 37, n. 132, p. 641-659, set./dez. 2007.

UNIVERSIDADE FEDERAL DA FRONTEIRA SUL. Grupo de Pesquisa em Educa- 
ção Popular/GRUPEPU. Relatório Evasão nos cursos de graduação da UFFS. Chapecó, 2014. 70p.

ZAGO, N.; PAIXÃO, L.P.; PEREIRA, T. I. Acesso e permanência no ensino superior: problematizando a evasão em uma nova universidade federal. Educação em Foco, Belo Horizonte, v. 19, n. 27, p. 145-169, jan./abr. 2016.

ZITKOSKI, J. J. A universidade na América Latina: algumas encruzilhadas diante do futuro de nosso continente. In: ZITKOSKI, J. J.; MORIGI, V. (Org.). Experiências emancipatórias e educação: a docência e a pesquisa. Porto Alegre: Corag, 2013, p. 13-25.

Data de recebimento: 10.09 .2019 Data de aceite: 10.07.2020 